\title{
Biological activity in soils treated with green manures of Lupinus spp. (Leguminosae) using the hydrolysis of fluorescein diacetate method (FDA) in Jalisco, Mexico
}

\begin{abstract}
The incorporation of legumes as green manures modifies some physical and chemical properties of soil, but its effects on some biological properties have not been evaluated. The current study aimed to evaluate the potential microbial activity of soil freshly amended with green manures of wild Lupinus species using the hydrolysis of fluorescein diacetate (FDA) method. Two wild lupine species (Lupinus exaltatus, L. rotundiflorus) with green manure potential were added at the rate of $44 \mathrm{t} \mathrm{ha}^{-1}$ to two different agricultural soils from Jalisco, Mexico, and incubated for 14 days under laboratory conditions. A treatment with maize $\left(\mathrm{control}^{+}\right)$as green manure and a treatment without addition of green manure (control-) were also included in the experiment. The enzymatic activity in terms of the hydrolysis of FDA was quantified at $1,3,7,10$, and 14 days. The FDA hydrolysis values fluctuated from 0.51 to $0.82 \mathrm{mg}$ fluorescein $\mathrm{kg}^{-1} \mathrm{~h}^{-1}$ in the treatments with green manure and from 0.10 to $0.13 \mathrm{mg}$ fluorescein $\mathrm{kg}^{-1} \mathrm{~h}^{-1}$ in the soil without green manure. L. rotundiflorus and maize yielded higher values of FDA hydrolysis compared with $L$. exaltatus. The addition of the organic amendments increased microbial activity measured as FDA hydrolysis.
\end{abstract}

Keywords: enzyme activity, microbial activity, lupine, organic matter, organic amendments
Volume 4 Issue 5 - 2020

Isidro Zapata Hernández,' Juan Francisco Zamora Natera,' Pedro Macedonio García López,' Eustacio Ramírez Fuentes, ${ }^{2} \mathrm{Ma}$ Nieves Trujillo Tapia ${ }^{2}$

'Centro Universitario de Ciencias Biológicas y Agropecuarias. Universidad de Guadalajara. México

${ }^{2}$ Instituto de Ecología. Universidad del Mar, México

Correspondence: Juan Francisco Zamora Natera. Centro Universitario de Ciencias Biológicas y Agropecuarias. Universidad de Guadalajara. Camino Ing. Ramón Padilla Sánchez No. 2100 , C.P. 45100 , Predio Las Agujas, Nextipac, Zapopan, Jalisco, México, Tel 3318942972 ,

Email jfzamoranatera@gmail.com

Received: October 01, 2020 | Published: October 13, 2020

\section{Introduction}

Microbial activity is a good general measure of organic matter turnover in natural habitats and in different agroecosystems, since generally more than $90 \%$ of the energy flow passes through microbial decomposers. ${ }^{1}$ The hydrolysis of fluorescein diacetate ( $3^{\prime}, 6^{\prime}$-diacetylfluorescein; FDA) is widely accepted as an accurate, sensitive, and simple method for measuring total microbial activity in a range of environmental samples, including soils. ${ }^{2}$ The FDA hydrolytic activity represents an estimation of microbial activity, showing the global hydrolytic capacity of the soil for microbial decomposition of organic matter (OM). ${ }^{3}$ Colorless FDA is hydrolyzed by both free and membrane-bound enzymes, such as proteases, lipases, and esterases, releasing the colored end product fluorescein which can be measured by spectrophometry ${ }^{4}$ or visualized within cells by fluorescence microscopy.

Fluorescein can also be quantified by fluorometry. ${ }^{1}$ Green et al. ${ }^{2}$ have used this technique to determine the impact of tillage on soil biological activity, while Floch et al. ${ }^{5}$ used this method to study the potential of soil enzyme activities as indicators of pesticide contamination. However, the hydrolysis of FDA, related to several soil hydrolases, has been little utilized to estimate the potential microbial activity of soil freshly amended with different organic materials. Prior research has show the benefits of using green manures (GMs) and other organic amendments to improve soil physical, chemical, and biological properties such as soil microbial populations and plant growth. $^{6}$

In Jalisco, Mexico, there is increasing interest in the potential use of some wild species of the genus Lupinus (Fabaceae = leguminosae) as GMs. For example, Zapata et al. ${ }^{7}$ estimated the biomass production and yield of $\mathrm{N}$ in Lupinus exaltatus, L. rotundiflorus, and $L$. mexicanus. ${ }^{7}$ However, the effects of these manures on the physical, chemical, and biological properties of the agricultural soils of Jalisco are not yet known. Thus, an experiment was conducted to evaluate microbial activity in regosol and luvisol soils from Jalisco amended with $L$. exaltatus and L. rotundiflorus as GMs. Three samples of each soil were collected at depths of $0-20 \mathrm{~cm}$ and a composite sample was obtained separately. They were dried and sieved using $2 \mathrm{~mm}$ diameter mesh. The materials used and incorporated into the soil as organic amendments were GMs of L. rotundiflorus (Figure 1), L. exaltatus and Zea mays, were produced during the spring-summer cycle of 2016-2017 in Zapopan, Jalisco, Mexico, as described by Zapata et al. ${ }^{8}$ (Figure 1).

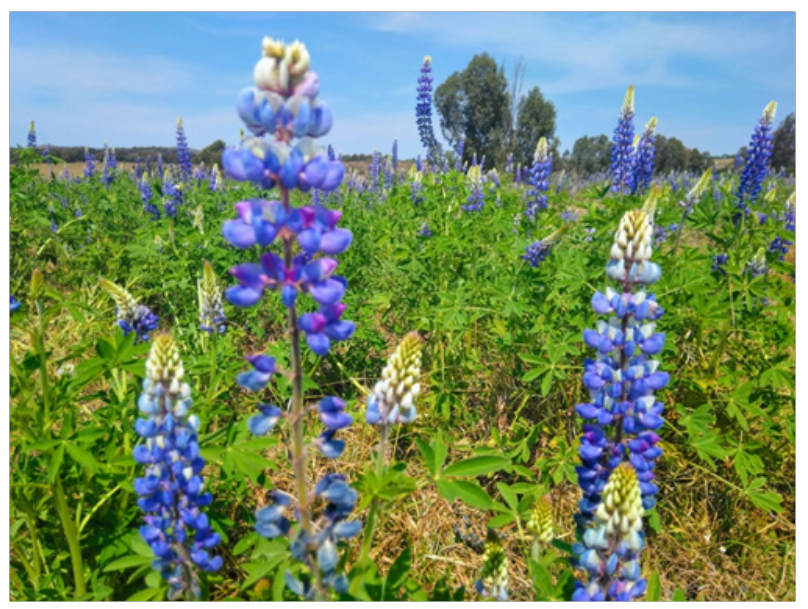

Figure I Wild Lupinus rotundiflorus growing in chiquilistlan, jalisco, Mexico. 
The plants were collected in the vegetative stage, dried in a forcedair oven at $65^{\circ} \mathrm{C}$ until completely dry, and ground to a particle size of $1 \mathrm{~mm}$, in accordance with the American National Standard Institute (ANSI/ ASTM). ${ }^{9}$ The chemical compositions of the plant materials before their incorporation into the soil as GM are shown in Table 1.

Soils for incubation with GMs and the control were used at a humidity sufficient to occupy $50 \%$ of their water retention capacity (WRC) and pre-incubated for 7 days. At day 8, $25 \mathrm{~g}$ portions of both soils were weighed and separately mixed with $0.4 \mathrm{~g}$ of the different organic amendments (L. rotundiflorus, L. exaltatus and maize).

They were then placed in flasks and kept in $1 \mathrm{~L}$ jars for incubation at room temperature $\left(23 \pm 2^{\circ} \mathrm{C}\right)$ for 14 days. The experiment was carried out in triplicate with its respective control (soil without organic amendment). The enzymatic activity in terms of FDA hydrolysis was quantified at $1,3,7,10$ and 14 days in each sample, following the method described by Green et al. ${ }^{1}$ The results obtained from the
FDA hydrolysis reaction were subjected to an analysis of variance (ANOVA) of repeated means. To compare the means, the Fisher test was used at a significance level of $\mathrm{P} \leq 0.05$.

At the end of 14 days of incubation, the FDA hydrolysis values (means of 5 evaluation periods) showed a significant difference between treatments $(\mathrm{P}<0.05)$ due to the effects of GMs and soil type. By comparing means, it was observed that the soils amended with organic material in the form of GM had the highest average FDA hydrolysis values compared with the non-amended control (soil without the addition of GM) (Figure 2). After 14 days incubation, mean released fluorescein levels varied from 0.51 to $0.82 \mathrm{mg}$ fluorescein $\mathrm{kg}^{-1} \mathrm{~h}^{-1}$ in the soils treated with GM and from 0.10 to 0.13 mg fluorescein $\mathrm{kg}^{-1} \mathrm{~h}^{-1}$ in the soil without GM. Soil microbial activity or soil enzyme activities, as measured by FDA hydrolysis, increased in both soils (luvisol and regosol), but with different results depending on the GM added (Figure 2).

Table I Chemical compositions of plant species used as GM in the aerobic incubation experiment (L. rotundiflorus, L. exaltatus, and maize)

\begin{tabular}{llllllll}
\hline \multirow{2}{*}{ Species } & \multicolumn{7}{l}{ Initial concentration (\%) } \\
\cline { 2 - 8 } & $\mathbf{C}$ & $\mathbf{N}$ & Lignin & Cellulose & Hemi cellulose & Lignin:N & C:N \\
\hline L. exaltatus & 42.48 & 3.06 & 19.85 & 35.69 & 17.35 & 6.48 & 14 \\
L. rotundiflorus & 39.52 & 3.26 & 18.62 & 35.09 & 17.38 & 5.71 & 12 \\
Maize & 42.02 & 1.74 & 7.52 & 38.3 & 26.57 & 4.32 & 24 \\
\hline
\end{tabular}

*Dry weight basis

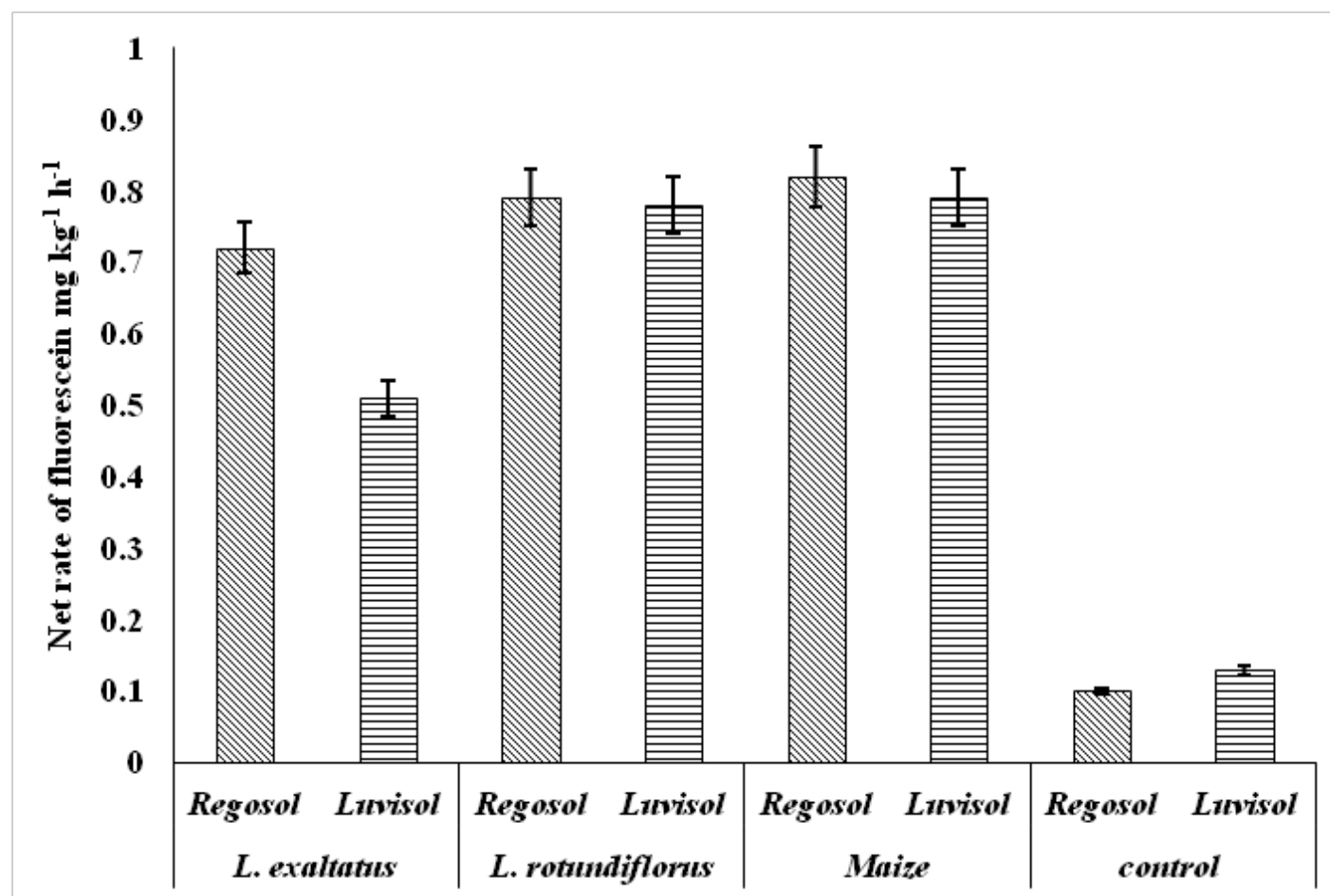

Figure 2 FDA hydrolytic activity ( $\mathrm{mg}$ of fluorescein $\left.\mathrm{kg}^{-1} \mathrm{~h}^{-1}\right)$ at the end of $\mathrm{I} 4$ days of incubation. The values is are the means for each soil type and treatment.

\section{Discussion}

Since most soils in Jalisco, Mexico, are limited in organic matter, it was not surprising that the addition of labile organic residues (i.e.,
GM) to the soil increased FDA hydrolytic activity (a general indicator of microbial activity). Increases in microbial activity after soils were amended with GM and other organic waste (e.g., sewage sludge, 
fresh and composted animal manure) have been reported previously. For example Carvalho et al..$^{10}$ in Brazil reported significant increases in FDA hydrolysis in soils amended with leguminous GMs such as Crotalaria, Mucuna, Canavalia, and Cajanus compared with the nonamended control. ${ }^{10}$ The values reported by these authors at 30 and 60 days of incubation in soil without organic amendment were 52.1 and $47.3 \mathrm{mg}$ of released fluorescein FDA kg-1 respectively. However, in the soils treated with Crotalaria and Cajanus GM, the released fluorescein FDA values increased up to $50 \%$ with respect to the control treatment, while with Canavalia and Mucuna GMs the values were $100 \%$ greater. Similarly, in this study all soils amended with GM displayed significantly higher levels of FDA hydrolysis than the nonamended control. Overall, after of 14 days of incubation, on average the lowest levels of FDA hydrolysis were registered with $L$. exaltatus, while the highest levels were found in soils amended with GMs of $L$. rotundiflorus and maize, but no significant differences between them were observed.

This likely indicates that the decomposition of L. exaltatus GM in the soils was slow compared with L. rotundiflorus and maize. In agreement with Hoitink and Boehm, ${ }^{11}$ FDA hydrolytic activity is a good indicator of the level of decomposition of soil organic matter. This may be related to some differences in the chemical compositions of the GMs used, as observed in other investigations. ${ }^{12,13}$ It is likely that the slightly higher lignin content and higher initial lignin-tonitrogen ratio in $L$. exaltatus tissues (Table 1 ) compared with $L$. rotundiflorus and maize increased the resistance of this species to attack by decomposer microorganisms. In this regard, Oglesby and Fownes ${ }^{14}$ and Talbot and Treseder ${ }^{15}$ reported a negative relationship between lignin content and litter decomposition dynamics. On the other hand, although the soils amended with L. exaltatus GM had less biological activity than soils amended with the other GMs studied, their FDA hydrolysis values were much higher than those of the non-amended soils used as controls. These values (means of five evaluation periods) differed significantly $(\mathrm{P}<0.05)$ among the evaluated soils (Figure 2). Ours results showed that the addition of GM increased the FDA hydrolysis levels of both soils compared with the non-amended control. Independently of the GM used, there was a general tendency to higher mean FDA hydrolysis values in regosol soil compared with luvisol soil. These values in regosol soil amended with $L$. exaltatus and maize were $30 \%$ and $8 \%$ higher, respectively, than the mean values obtained in luvisol soil.

On the other hand, although FDA hydrolysis levels were also higher in regosol soil than in luvisol soil with the incorporation of $L$. rotundiflorus ( 0.79 vs. $0.77 \mathrm{mg}$ of fluorescein $\left.\mathrm{kg}^{-1} \mathrm{~h}^{-1}\right)$, they were not significantly different $(\mathrm{P}>0.05)$. This indicates that microbial activity in terms of decomposition was slower in luvisol soil than in regosol soil. This can be explained as a function of the chemical and physical compositions of the soils. In this work we consider that differences in the physical compositions of the soils, especially, were probably what caused the variation in the levels of FDA hydrolysis. In this regard, many researchers have observed that organic residues decompose and mineralize more slowly in soils with higher clay contents, especially clays that have higher exchange capacities. ${ }^{13,16}$ In this study the luvisol soil had a higher clay content than the regosol soil (42 vs. 17\%, respectively), and according to Thönnissen the reduced aeration or lower oxygenation for the microorganisms in clay soils compared with sandy soils may contribute to slowing the decomposition of organic residues. ${ }^{13}$

\section{Conclusion}

Soil microbial activity, as measured by FDA hydrolysis, increased with the use of GM as compared with the soils without GM. Lupinus rotundiflorus and maize yielded higher values of FDA hydrolysis than did L. exaltatus.

\section{Acknowledgments}

This work was financially supported by CONACYT, thru a scholarship awarded to Isidro Zapata Hernandez.

\section{Conflicts of interest}

Authors declare no conflict of interest exists.

\section{References}

1. Green, V S., Stott DE, Diack, M. Assay for fluorescein diacetate hydrolytic activity: optimization for soil samples. Soil Biology and Biochemistry. 2006;38(4):693-701.

2. Green VS, Stott DE, JC Cruz, et al. Tillage impacts on soil biological activity and aggregation in a Brazilian Cerrado Oxisol. Soil and Tillage Research. 2007;92:114-121.

3. Sánchez-Monedero MA, Mondini C, Cayuela ML, et al. Fluorescein diacetate hydrolysis, respiration and microbial biomass in freshly amended soils. Biology and Fertility of Soils. 2008; 44(6):885-890.

4. Adam G, and Duncan H. Development of a sensitive and rapid method for the measurement of total microbial activity using fluorescein diacetate (FDA) in a range of soils. Soil Biology and Biochemistry. 2001; 33(7-8):943-951.

5. Floch $\mathrm{C}$, Chevremont $\mathrm{AC}$, Joanico $\mathrm{K}$, et al. Indicators of pesticide contamination: soil enzyme compared to functional diversity of bacterial communities via Biolog® Ecoplates. European Journal of Soil Biology. 2011;47(4):256-263.

6. Flavel TC, Murphy D.V. Carbon and nitrogen mineralization rates after application of organic amendments to soil. Journal of Environmental Quality. 2006; 35:183-197.

7. Zapata HI, Rodríguez MR, García LPM, et al. Dry matter yield and nitrogen content in Lupinus spp. (Leguminosae) with potential as a green manure. Legume Research. 2019; 42 (4):523-527.

8. Zapata-Hernández I, Zamora-Natera, JF, Trujillo-Tapia, MN, et al. ¿La incorporación de residuos de diferente especie de Lupinus, como abono verde afecta la actividad microbiana del suelo?. Terra Latinoamericana. 2020; 38:45-56.

9. American national standard institute (ANSI / ASTM).

10. Carvalho NS, Oliveira ABB, Pessoa MMC, et al. Short-term effect of different green manure on soil chemical and biological properties. African Journal of Agricultural Research. 2015;(43):4076-4081.

11. Hoitink HAJ, Boehm MJ. Biocontrol with in the context of soil microbial comunities: a substrate-dependent phenomenon. Annual Review Phytopathology. 1999;37:427-446.

12. Melillo JM, Aber JD, Muratore, JF. Nitrogen and lignin control of hardwood leaf litter decomposition dynamics. Ecology. 1982; 63(3):621-626.

13. Thönnissen C, Midmore DJ, Ladha, JK, et al. Legume decomposition and nitrogen release when applied as green manures to tropical vegetable production systems. Agronomy Journal. 2000;92:253-260. 
14. Oglesby KA, Fownes, JH. Effects of chemical composition on nitrogen mineralization from green manures of seven tropical leguminous trees. Plant and Soil, 1992;43(1):127-132.

15. Talbot JM, Treseder, KK. Interactions among lignin, cellulose, and nitrogen drive litter chemistry-decay relationships. Ecology, 2012;93(2):345-354.
16. Odhiambo JJ. Decomposition and nitrogen release by green manure legume residues in different soil types. African Journal of Agricultural Research. 2010;5(1):90-96. 